\title{
Quantum gravity: yesterday and today
}

\author{
Bryce DeWitt
}

Published online: 12 February 2009

(C) Springer Science+Business Media, LLC 2009

\section{Erratum to: Gen Relativ Gravit (2009) 41:413-419 DOI 10.1007/s10714-008-0719-0}

Unfortunately, several errors occurred in the original version of this paper:

p. 414, line 30: a footnote 2 should be inserted after "human mind"; footnote 2: See for instance J.P. Changeux and A. Connes "Matiere a pensee" (O. Jacob 1992)

p. 415, line 2: "1961" should be "1962"

p. 416, line 13: "Strefel" should be "Stieffel"

p. 416, line 43: a footnote 3 should be inserted after "spin-foam"; footnote 3: A. Corichi suggests that B. DeWitt meant "spin network"

p. 419, ref. 15, line 1: "This book" should be "Ref. 14"

p. 419, ref. 26: the reference should read: Debever, R.: Elie Cartan and Albert Einstein: Letters on Absolute Parallelism 1929-1932. Original text in French/ German, English translation by Leroy, J., Ritter, J. Princeton University Press, Princeton NJ 1979

The online version of the original article can be found under doi:10.1007/s10714-008-0719-0.

B. DeWitt

Austin, TX, USA

e-mail for correspondence: cdewitt@physics.utexas.edu 